\title{
How to Study the History of Philosophy of Science?
}

\author{
Xing Cheng Ma* \\ Hongkong Polytechnic University, Hongkong \\ *Corresponding author: Xing Cheng Ma, Hongkong Polytechnic University, Hongkong \\ To Cite This Article: Xing Cheng Ma. How to Study the History of Philosophy of Science?. Am J Biomed Sci \& Res. 2019 - 1(4). AJBSR.MS.ID.000531. \\ DOI: $10.34297 / A J B S R .2019 .01 .000531$
}

Received: February 15, 2019 | Published: February 22, 2019

\section{Mini Review}

Undoubtedly, this paper [1] impressed me deeply. How to study the history of philosophy of science? Previous researchers either took philosophers of science as clues to introduce in detail the ideas and methods of philosophers of Science in different periods, or take a concept of the philosophy of science, such as the structure of scientific theory, the evolution of scientific theory, as a clue, to elaborate the understanding of this concept and related theories of different schools of philosophy of science. There are many studies around the above clues, some of the which are also very good. The author of this paper, however, puts forward a new clue to study the history of philosophy of science, that is, to raise and solve the problems of philosophy of science.

The development of the philosophy of science, from the logical path to the historical path, and to the path of the combination of the logic and history, produced many different styles of schools and theories of the philosophy of science. The author finds that regardless of the what kind of theoretical forms appearing in the development of philosophy of science, "problem-oriented" methodology has always been the same. "In fact, the thinking of philosophers of science have been based on two major issues, namely, the rationality of the scientific problem itself and of the development of scientific problems [2]." Take the examples of famous theories of philosophy of science as part of logical empiricism, historicism or new historicism, this paper attempts to illustrate how philosophers of science think and construct the theory around the two issues. This is of great significance to the development of future philosophy of science. Regretfully, there are few studies in this area, and almost no relevant results can be seen.

The author argues that, through a more in-depth study, the history of philosophy of science is a problem-oriented history of probing the growth and progress of scientific knowledge. If there is no investigation and analysis of "problem", the philosophers cannot explain "theory" clearly. Starting from searching for meaningful problems, logical positivists explored the nature and characteristics of the sentence and sentence system. They turned the absolute legitimacy of problem into the relative, regarded the development of science as a cumulative and gradual process of legitimate problems. Popper grasped, in the dynamic evolution of problem, the legitimacy of problem, considering the scientific progress as a sudden proliferation of problems through falsification of a scientific theory.

Lakatos' problem-shift theory is sophisticated processing of Popper's four-stage schema, which illuminates the legitimacy of a problem and its development [3]. Kuhn described the legitimate development of problem more comprehensively, depicted the periodical cumulative characteristics and revolutionary non-cumulative characteristics of the legitimate problems through normal problems, empirical anomalous problems, and revolutionary problems [4]. Based on research traditions, Laudan gave a detailed sub-division of the problem itself, described and normalized scientific progress through the legitimate conversion of the problem, provided a more objective historical description and strong philosophical support for open and free scientific inquiry activities.

We can see that the author not only depicts the philosophical problems and solutions put forward by philosophers of science but also carefully analyses the relationship between the problem theories of different philosophers of science, thus revealing the development process of the philosophy of Science in the perspective of problems. For example, the author believes that the division of observational words and theoretical words by logical positivists may be a source of Laudan's problem-solving theory [5].

The observational vocabulary corresponds to the empirical problem, and the theoretical corresponds to the conceptual. Its natural theoretical consequence is that scientific progress lies in solving more and more empirical and conceptual problems. The solution of conceptual problems must be reduced to empirical problems. Carnap put forward the concept of "logical probability", replace "verification" with "confirmation", "complete truth" with "probability truth."

Accordingly, the constitutive elements of a legitimate problem turn from one single proposition to a compound one, from a 
completely true proposition to a probability one. The degree of legitimacy of the problem is changed from the original absolute to the relative. The author infers that this may directly inspire historians' perceptions of scientific problems. Lakatos does not reject Popper's four-stage schema, but rather deal with the theoretical and trial-and-error links in a refined way. The research programme at the progressive stage is more likely to be falsified because of its excess empirical contents, leading to a progressive problem shift for the research program at the degenerating stage, the likelihood of its being falsified will be reduced because of the reduction of its empirical contents, resulting in a degenerating problem shift [6].

In this way, the author deems that Lakatos's theory is going beyond Popper's because his theory can describe the diachronic changes of the legitimacy of the problem.

In a word, this paper emphasizes the problem-oriented study of the history of philosophy of science and points out a new direction for the study of the history of philosophy of science. In my opinion, the circle of the philosophy of science should attach importance to this direction and produce more research results.

\section{References}

1. Ma L (2017) On Problem-oriented Philosophy of Science. Philosophical Researches 3: 118-126.

2. Ma L (2017) On Problem-oriented Philosophy of Science. Philosophical Researches 3(118).

3. Karl Popper (1963) Conjectures and Refutations. London, Routledge.

4. Kuhn TS (1970) The Structure of Scientific Revolutions $\left(2^{\text {nd }}\right.$ edn), University of Chicago Press, Chicago and London, USA.

5. Larry Laudan (1977) Progress and Its Problems. Berkeley, University of California Press.

6. Lakatos I (1978) The Methodology of Scientific Research Programmers. Cambridge, USA. 